\title{
Uso de prototipagem rápida no planejamento de reconstruções da artroplastia total do quadril: Uma ferramenta para ensino*
}

\section{Use of 3D Printing in Planning the Reconstruction of Total Hip Arthroplasty: A Teaching Tool}

\author{
Marina Cornelli Girotto ${ }^{1,20}$ Rafael de Luca de Lucena ${ }^{2(1)}$ Carlos Roberto Schwartsmann $2,3(0)$ \\ Ary da Silva Ungaretti Neto ${ }^{2 \odot}$ Gisele Orlandi Introini ${ }^{4}$ Leandro de Freitas Spinelli ${ }^{3,5}$
}

${ }^{1}$ Serviço de Ortopedia e Traumatologia, Universidade Federal de Ciências da Saúde de Porto Alegre, Porto Alegre, RS, Brasil

2 Serviço de Ortopedia e Traumatologia, Santa Casa de Misericórdia de Porto Alegre, Porto Alegre, RS, Brasil

${ }^{3}$ Departamento de Clínica Cirúrgica, Faculdade de Medicina, Universidade Federal de Ciências da Saúde de Porto Alegre, Porto Alegre, RS, Brasil

${ }^{4}$ Departamento de Ciências Básicas da Saúde, Universidade Federal de Ciências da Saúde de Porto Alegre, Porto Alegre, RS, Brasil

5 Programa de Pós-Graduação em Projetos e Processos de Fabricação, Laboratório de Bioengenharia, Biomecânica e Biomateriais,

Universidade de Passo Fundo, Passo Fundo, RS, Brasil
Endereço para correspondência Marina Cornelli Girotto, MD, Serviço de Ortopedia e Traumatologia - Santa Casa de Misericórdia de Porto Alegre, Rua Professor Annes Dias, 135, 20 andar, Centro Histórico, Porto Alegre, Rio Grande do Sul, 90460-150, Brasil (e-mail: marinacgirotto@gmail.com).

Rev Bras Ortop 2021;56(6):809-812.

\begin{abstract}
Resumo
O objetivo deste trabalho é demonstrar como os biomodelos podem servir como ferramenta de ensino para o esclarecimento de técnicas cirúrgicas e o treinamento em um serviço de residência médica.

Foram realizadas séries de casos em nosso ambulatório de ortopedia e traumatologia,

Palavras-chave

- artroplastia do quadril

- quadril/cirurgia

- impressão tridimensional

- modelos anatômicos nos quais o uso da prototipagem para o planejamento cirúrgico contribuiu para o ensino cirúrgico e treinamento de médicos residentes. Dois casos foram selecionados como exemplo neste artigo.

$\mathrm{O}$ uso de biomodelos permite um melhor entendimento da cirurgia pela equipe cirúrgica e pelos residentes, e diminui o tempo e os riscos cirúrgicos aos pacientes. O uso de biomodelos no planejamento de reconstruções da artroplastia total do quadril pode servir como um bom método de ensino, para a avaliação e previsão das dificuldades no momento da cirurgia, e para otimizar os procedimentos.
\end{abstract}

\footnotetext{
Trabalho desenvolvido no Serviço de Ortopedia e Traumatologia da Santa Casa de Misericórdia de Porto Alegre e na Universidade Federal de Ciências da Saúde de Porto Alegre, Rio Grande do Sul, com a colaboração do Laboratório de Bioengenharia, Biomecânica e Biomateriais da Universidade de Passo Fundo, Rio Grande do Sul, Brasil.
}

recebido

23 de Agosto de 2020

aceito

01 de Dezembro de 2020

Publicado on-line

Agosto 13, 2021
DOI https://doi.org/ 10.1055/s-0041-1726064. ISSN 0102-3616. (c) 2021. Sociedade Brasileira de Ortopedia e Traumatologia. All rights reserved.

This is an open access article published by Thieme under the terms of the Creative Commons Attribution-NonDerivative-NonCommercial-License, permitting copying and reproduction so long as the original work is given appropriate credit. Contents may not be used for commercial purposes, or adapted, remixed, transformed or built upon. (https://creativecommons.org/ licenses/by-nc-nd/4.0/)

Thieme Revinter Publicações Ltda., Rua do Matoso 170, Rio de Janeiro, RJ, CEP 20270-135, Brazil 

Abstract
The present study aims to demonstrate how biomodels can be used as teaching tools for surgical techniques and training in a medical residency service.
Keywords
- arthroplasty, replacement, hip
- hip/surgery
- printing, three- dimensional
- models, anatomic
A case series was carried out in our orthopedics and traumatology outpatient facility using three-dimensional (3D) printing for surgical planning to contribute to the surgical teaching and training of resident physicians. Two cases were selected as examples in the present article. Biomodels enable a better understanding of the surgery by the surgical team and residents, reducing the surgical time and the risks for the patients.
These models can be a good teaching method to plan reconstructions of total hip arthroplasties, evaluate and predict surgical difficulties, and optimize procedures.

\section{Introdução}

A prototipagem rápida pode ser resumida como uma forma de se reproduzir fisicamente modelos virtuais tridimensionais (3D) pela deposição de um material por camadas, podendo-se utilizar várias técnicas. ${ }^{1}$ A deposição física por camadas possibilita uma grande liberdade de criação de formas geométricas, que seriam difíceis ou até mesmo impossíveis de se obter por técnicas industriais convencionais, como a usinagem e outras, baseadas em remoção de material. ${ }^{2} \mathrm{~A}$ técnica tem se mostrado de grande valia para a reprodução de estruturas orgânicas vivas, como tecidos e órgãos, uma vez que elas não apresentam formas perfeitas (ou seja, constituem poliedros regulares), e que sua arquitetura é feita a partir de crescimento celular, que é particular de cada indivíduo, respeitando diversos fatores tanto genéticos quanto ambientais. ${ }^{3}$ A diversidade fenotípica é absolutamente elevada no Homo sapiens. Portanto, a competência da práxis médica se dá pela intervenção/interação nos inúmeros pacientes que exibem características anatômicas heterogêneas.

A crescente busca pela excelência no diagnóstico e no tratamento das alterações osteomusculares tem se tornado um grande desafio para os ortopedistas. Nesse sentido, a incorporação de novas tecnologias no diagnóstico por imagem e no planejamento de terapêuticas avançadas, como as cirurgias reparadoras e reconstrutivas, é algo que deve ser feito na prática médica desde o início da formação ortopédica. ${ }^{3}$ Mothes et al. ${ }^{4}$ utilizaram a prototipagem para estudos de defeitos glenoumerais no planejamento de artroplastias de ombro. Em sua dissertação de mestrado, Marques ${ }^{5}$ testou vários modelos de prototipagem que poderiam ser aplicados na área de traumatologia para o planejamento de implantes na osteossíntese.

Os biomodelos de prototipagem podem ser obtidos no âmbito médico a partir de imagens de tomografia computadorizada (TC) ou ressonância magnética $(\mathrm{RM}) \cdot{ }^{4} \mathrm{~A}$ técnica já é amplamente difundida na prática médica e na cirurgia ortopédica e traumatológica, e tem sido utilizada para facilitar o entendimento das deformidades e falhas ósseas. ${ }^{3}$ Além disso, 0 conhecimento prévio da estrutura pode acarretar também um menor tempo cirúrgico, diminuindo riscos aos pacientes. ${ }^{4}$

\section{Descrição da Técnica}

O objetivo da presente nota técnica é demostrar como o uso da prototipagem rápida (impressão em 3D) pode ser incluída como ferramenta para a compreensão de técnicas cirúrgicas eaprimorar o treinamento de equipes em um serviço de residência médica.

Para os casos clínicos apresentados, foram realizados treinamentos cirúrgicos nos modelos de prototipagem rápida. Para a realização dos modelos 3D, foram necessárias duas etapas. Inicialmente, foram solicitadas TCs dos pacientes, e, posteriormente, as imagens obtidas foram processadas no software livre InVesalius (CTI Renato Archer, Campinas, SP, Brasil) e posteriormente no MeshMixer (Autodesk, Inc., San Rafael, CA, EUA). Os biomodelos foram feitos com uma impressora 3D Cliever (Cliever Tecnologia, Belo Horizonte, MG, Brasil) utilizando filamento de ácido polilático (polylactic acid, PLA, em inglês). Para os casos clínicos apresentados, foram realizados treinamentos cirúrgicos nos modelos de prototipagem impressos.

Ambos os procedimentos foram realizados conforme a técnica preconizada, e, posteriormente, seguidos conforme as rotinas do Serviço de Ortopedia e Traumatologia. No transoperatório, foi utilizada a técnica planejada durante o treinamento.

Os critérios de inclusão no trabalho foram pacientes que apresentavam importantes falhas e deformidades ósseas, e para os quais haviam sido solicitados exames de imagem de TC de forma a se mensurar as dimensões tridimensionais dos defeitos. Um modelo impresso em 3D foi realizado para cada um dos casos e comparado posteriormente com a situação real in loco. A descrição detalhada de todo o procedimento foi realizada.

Foram considerados também neste trabalho dados de prontuário, codificados para que as identidades dos pacientes fossem mantidas de forma anônima, que incluíram parâmetros pré, peri e pós-operatórios, além da avaliação dos exames de imagem e dos modelos impressos. Esse trabalho foi submetido e aprovado pelo comitê de ética hospitalar.

\section{Caso 1}

Paciente feminina de 77 anos, com histórico de artroplastia de quadril cimentada à direita devido a coxartrose primária realizada havia 17 anos no mesmo serviço. A mesma queixava-se de dor com evolução havia três anos no quadril operado. Nas radiografias de seguimento ambulatorial, foram observadas osteólise periacetabular e soltura com rotação do componente acetabular, demonstrando, assim, falha do componente acetabular. Não foram observadas alterações significativas no componente femoral em relação aos exames de imagem prévios (-Figura 1A,B). 


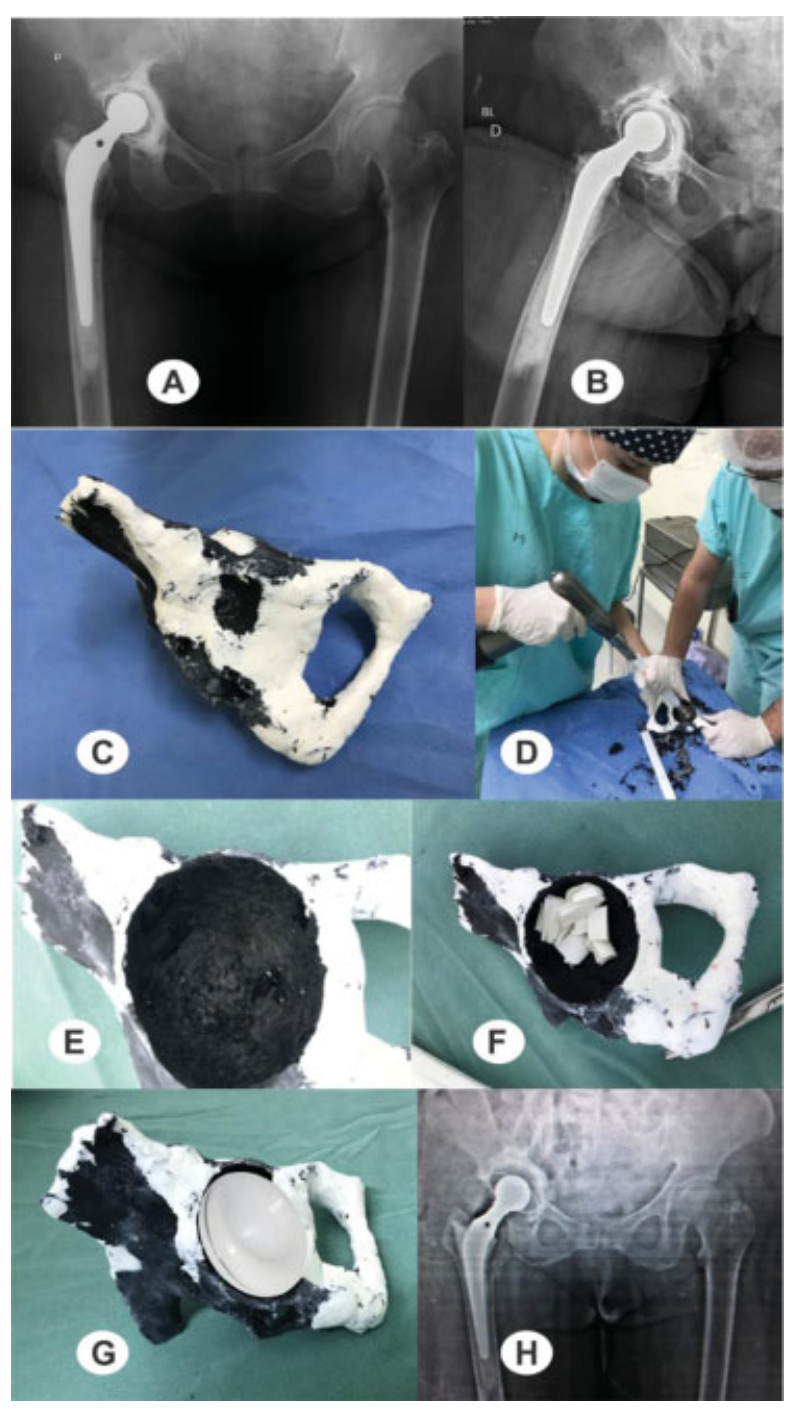

Fig. 1 Radiografias de bacia (A) e perfil do quadril direito (B) préoperatórias da paciente no momento da revisão; observa-se uma importante falha óssea acetabular com soltura deste componente. (C) Vista do modelo de prototipagem impresso; (D) treinamento de residentes com os modelos de prototipagem; (E) cavidade observada e (F) preparação do acetábulo com visualização do defeito ósseo e seu preenchimento com osso picado e impactado; (G) planejamento do tamanho do implante e seu posicionamento; $(\mathrm{H})$ radiografia pósoperatória da revisão de artroplastia total do quadril direito.

Na - Figura 1C, observa-se a hemipelve impressa para a melhor avaliação do defeito ósseo e o treinamento dos residentes. Sustentou-se a hipótese diagnóstica de falha acetabular de provável origem asséptica, visto que a paciente não apresentava sinais clínicos e laboratoriais de infecção. Dessa forma, foi indicada a revisão do componente acetabular ( - Figuras 1D,E,F,G), utilizando-se enxerto ósseo picado e impactado no teto e fundo acetabulares. A radiografia de bacia do pós-operatório se encontra na - Figura $\mathbf{1 H}$.

\section{Caso 2}

Paciente masculino de 61 anos com histórico de artroplastia de quadril à esquerda havia 18 anos por fratura do acetábulo e posterior revisão da artroplastia havia 6 anos. 0 paciente relatava dor havia pelo menos 5 anos, com evolução progressiva no quadril esquerdo associado a perda funcional importante. Durante este período, o paciente se consultou com diversos colegas, que orientaram conduta expectante ou a retirada dos implantes, por não haver mais possibilidades terapêuticas de acordo com sua experiência. Observamos que, nas imagens das radiografias pré-operatórias, o paciente apresentava prótese total de quadril não cimentada, com o componente acetabular solto e com extensa erosão acetabular, rupturas de malha de aço, e fraturas de parafusos ( - Figura 2A,B). Não foram observadas alterações significativas no componente femoral, e o paciente tampouco apresentava sinais clínicos ou laboratoriais de infecção. Uma TC foi solicitada para uma melhor avaliação do defeito ósseo, e posteriormente realizou-se a prototipagem do quadril ( - Figuras 2C,D,E). Considerando-se a extensa lesão óssea, pensamos inicialmente no uso de osso de Banco de Ossos, mas não dispomos de um em nossa cidade. Então, realizou-se o treinamento dos residentes e da equipe, por meio de montagens com metal trabeculado e enxertia óssea no interespaço (-Figuras 2F,G,H,I). Dada a gravidade da lesão, pensamos inicialmente na opção de dois acetábulos proposta por Paproski, mas as circunferências das cunhas não se encaixavam adequadamente. Então, pensamos em uma nova opção estrutural, com duas cunhas e um sistema de ancoragem com parafusos divergentes, preenchido com enxerto ósseo, sobre o qual colocamos o novo acetábulo e cimentamos um acetábulo na inclinação e anteversão adequados. O procedimento cirúrgico ocorreu exatamente como o planejado, poupando muito tempo em uma cirurgia já de grande porte, e ocorreu com pouco sangramento (-Figuras 2],K,L,M,N). A radiografia pós-operatória se mostrou satisfatória (-Figura 20), e observou-se uma perfeita integração do enxerto e ótima função no paciente com três anos de seguimento ( - Figura 2P). No momento, o paciente está assintomático e satisfeito com o procedimento.

\section{Discussão}

A presente pesquisa avaliou diferentes casos de revisão de artroplastia total de quadril envolvendo a utilização de impressão 3D no planejamento cirúrgico e o treinamento de médicos residentes de ortopedia e traumatologia. Diversos autores já endossaram a importância do uso de tal tecnologia no planejamento pré-operatório. Mothes et al., ${ }^{4}$ por exemplo, citam a importância da prototipagem para o planejamento pré-operatório no tratamento das deformidades ósseas no ombro, e sustentam que ela minimiza o risco de intercorrências intraoperatórias, em uma tentativa de aprimorar os resultados.

O tempo do tratamento da imagem obtida pela TC fica em torno de um turno, pois é necessário corrigir e remover artefatos, implantes, e falhas de volumes que possam haver. Considerando a impressão em si, o tempo gira em torno de $16 \mathrm{~h}$, dependendo do preenchimento escolhido (densidade do material). O custo médio da impressão do biomodelo é de 56 reais ( $\sim 10$ dólares) por peça. Ressaltamos que as bacias são cortadas no software para se imprimir apenas a área compreendida entre a sínfise púbica e a região sacroilíaca ipsilateral.

O uso de modelos obtidos por prototipagem pode simplificar a visualização tridimensional de diferentes patologias, e facilitar o entendimento do planejamento de 


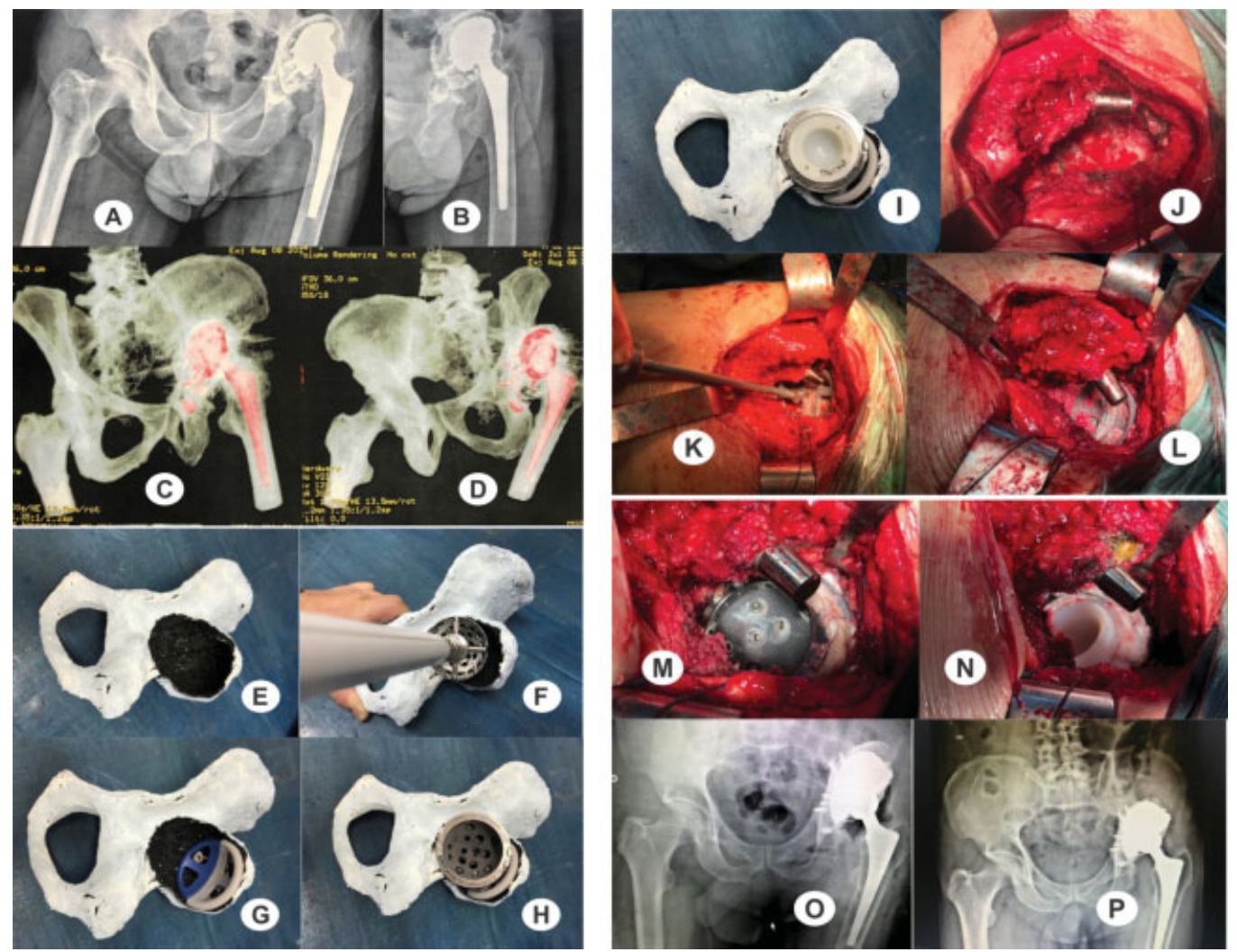

Fig. 2 (A, B) radiografias pré-operatórias da bacia e de perfil do quadril esquerdo do paciente; (C, D) vistas da tomografia computadorizada; (E) visualização da extensa lesão acetabular; (F) estudo da situação; (G) montagem de uma nova disposição de uso de metal trabeculado e estudo de sua ancoragem; (H) colocação do novo acetábulo; (I) posicionamento do polietileno cimentado; (J) visualização da lesão intraoperatória (observar a quase ausência do teto acetabular e das paredes anterior e posterior); (K) montagem da estrutura de metal trabeculado; (L) colocação dos parafusos divergentes e enxerto ósseo picado e impactado; (M) colocação do acetábulo de metal trabeculado, lembrando de passar uma fina camada de cimento entre os metais para evitar contato metálico; (N) cimentação do acetábulo na posição adequada; (O) radiografia pós-operatória imediata; e (P) radiografia com três anos de pós-operatório (observar a integração do enxerto).

procedimentos cirúrgicos complexos, o que amplia o conhecimento anatômico, radiológico e cirúrgico.

\section{Considerações Finais}

Neste trabalho, observamos a necessidade de se modificar a técnica cirúrgica pelo treinamento no protótipo, utilizando uma nova disposição do metal trabeculado. Incluir estas tecnologias no reportório do preceptor é fundamental para a diferenciação do futuro especialista no mercado de trabalho, uma vez que é imprescindível que o ensino médico se adapte de modo a formar profissionais capazes de responder às demandas da sociedade. Portanto, a prototipagem rápida pode aliar a conveniência do treinamento pré-operatório com o uso da tecnologia nas cirurgias ortopédicas, e deve, na medida do possível, ser difundida no ambiente de ensino médico. Salientamos que o presente trabalho não tem aplicação somente na ortopedia e traumatologia, mas em todas as áreas da medicina.

\section{Suporte Financeiro}

Não houve suporte financeiro de fontes públicas, comerciais, ou sem fins lucrativos.

Conflito de Interesses

Os autores declaram não haver conflito de interesses.

\section{Agradecimentos}

Os autores agradecem a Gabriel Severo da Silva por suas contribuições ao presente trabalho, assim como ao Prof. Dr. André Peres, Samuel Werner Wolf, Luis Fernando Marcelino Braga, Andreia Gomes Aires do LIPECIN/UFCSPA, Prof. Charles Leonardo Israel e ao técnico Derli da Rosa da UPF.

\section{Referências}

1 Oliveira MF, Maia IA, Noritomi PY, Nargi CG. Construção de Scaffolds para engenharia tecidual utilizando prototipagem rápida. Materia (Rio J) 2007;12(02):373-382

2 Bagaria V, Deshpande S, Rasalkar DD, Kuthe A, Paunipagar BK. Use of rapid prototyping and three-dimensional reconstruction modeling in the management of complex fractures. Eur J Radiol 2011;80(03):814-820

3 Yang S, Leong KF, Du Z, Chua CK. The design of scaffolds for use in tissue engineering. Part II. Rapid prototyping techniques Tissue Eng 2002;8(01):1-11

4 Mothes FC, Britto A, Matsumoto F, Tonding M, Ruaro R. O uso da prototipagem tridimensional para o planejamento do tratamento das deformidades ósseas do úmero proximal. Rev Bras Ortop 2018;53(05):595-601

5 Marques TMR. Definição de um modelo de planeamento pré operatório em ortopedia usando imagem digital [dissertação]. Porto, Portugal: Faculdade de Engenharia da Universidade do Porto, Portugal; 2013 